\title{
Study on Tourism Network Marketing of Dabie Mountain in Huanggang Zhentang $\mathrm{Ke}^{1, \mathrm{a}}$, San Qin ${ }^{1, \mathrm{~b}}$ \\ ${ }^{1}$ School of Business, Huanggang Normal University, Huanggang, Hubei, 438000 \\ a email, ${ }^{b}$ email
}

Keywords: Hubei Dabie Mountain, Tourism Network Marketing, Huanggang

\begin{abstract}
In recent years, the Dabie Mountains using the Dabie Mountain tourism resources to actively develop tourism, some new marketing methods have been quickly integrated into the development of tourism, with the network tourism marketing has become a new trend. Online travel has become a popular way to accept the more convenient, fast and fast way of travel. To this end, this paper combines the development status of Huanggang Dabie Mountain tourist area and the status quo of tourism network marketing, summed up the problem, proposed for the Huanggang Dabie Mountain area more effective tourism network marketing recommendations.
\end{abstract}

\section{Introduction}

Huanggang Dabie Mountain is an important part of the entire Dabie Mountain tourist area, the main red tourism, green eco-tourism and cultural landscape tourism. From January to October in 2016, Huanggang City received 21 million domestic and foreign tourists, an increase of $21 \%$, to achieve comprehensive tourism income of 12.5 billion yuan, an increase of 23\%.

Table 12012 - 2016 Hokkaido Dabie Mountain County Reception (unit: million)

\begin{tabular}{lccccc} 
City & 2012 & 2013 & 2014 & 2015 & 2016 \\
\hline Hongan & 252 & 330 & 425 & 509 & 618.28 \\
Macheng & 218 & 298 & 360 & 480 & \\
Luotian & 325 & 248 & 385 & 465 & 535 \\
Yingshan & 115 & 135.4 & 206 & 360 & 450 \\
Huangmei & 60 & 126 & 196.6 & 242.5 & 279.2 \\
Qichun & & 103 & 96 & 203.81 &
\end{tabular}

Table 1 shows that the number of tourist reception and tourism income in the Dabie Mountains of Hokkaido are increasing year by year, and the growth situation is relatively good. 
Table 2 Huanggang Dabie Mountain area tourist attractions reception and income situation

\begin{tabular}{ccccc}
\hline & \multicolumn{2}{c}{2007} & \multicolumn{2}{c}{2013} \\
Tourist attractions & $\begin{array}{c}\text { Reception (ten } \\
\text { thousand Person) }\end{array}$ & $\begin{array}{c}\text { Travel income } \\
\text { (ten thousand } \\
\text { yuan) }\end{array}$ & $\begin{array}{c}\text { Reception (ten } \\
\text { thousand Person) }\end{array}$ & $\begin{array}{c}\text { Travel income } \\
\text { (ten thousand } \\
\text { yuan) }\end{array}$ \\
\hline $\begin{array}{c}\text { Yinshan Kowloon } \\
\text { Grand Canyon } \\
\text { Ma Cheng Guifeng } \\
\text { Mountain tourist } \\
\text { scenic spot }\end{array}$ & 10 & 1000 & 35 & 6200 \\
$\begin{array}{c}\text { Hongtian Tiantai } \\
\text { Mountain Scenic } \\
\text { Area }\end{array}$ & 13.7 & 8400 & 47 & 170000 \\
$\begin{array}{c}\text { Xishui Triangle } \\
\text { Mountain Tourism } \\
\text { Scenic Area }\end{array}$ & 18.6 & 459 & 50 & 180000 \\
$\begin{array}{c}\text { Huangmei Wuzu } \\
\text { Temple }\end{array}$ & 16 & 3350 & 40 & 110000 \\
\hline
\end{tabular}

From Table 2 can be seen in Huanggang Dabie Mountain tourist area attractions tourist reception and tourism income was significantly changed, rapid increase in tourism efficiency, Huanggang Dabie Mountain tourism scenic tourism development potential is huge.

According to the China Internet Information Center on January 22, 2016 issued the 37th survey report, as of December 2015, the scale of Chinese Internet users reached 688 million, the Internet penetration rate of 50.3\%; mobile phone users scale of 620 million, accounting for up to $90.1 \%$ The With the development of the network as well as the improvement of the economic level people are increasingly keen to travel in the holidays. According to the "2016-2017 China Online Travel Market Research Report" content shows that in 2016, China's online holiday market transactions of about 114 billion yuan, compared with 75.5 billion yuan in 2015 increased by 50.9\%, online penetration rate of $25.7 \%$ Year $20.1 \%$ growth of about 5.6 percentage points, online penetration gradually expanded. These figures show that the number of Internet users in China not only greatly increased but also shows that more and more people will try to use the Internet for tourist sites, hotels, lines and other key information options.

Huanggang Dabie Mountain tourism network marketing status quo, this article from the official tourism website, forum posting situation, QQ group establishment, WeChat public number, micro-blogging platform open and professional travel site cooperation between the cooperation with the mainstream video site, Whether the use of tourist attractions activities such as event marketing and other aspects of investigation and collection, you can find the vast majority of Dabie Mountain in Huanggang County and tourist attractions have established an official travel site, and a few counties (Xishui County) and tourist attractions did not establish the official website The Through the survey, we found that the various counties and tourist attractions, although there are corresponding travel sites, but the form is greater than the content, compared with the current mainstream travel site platform, due to the lack of tourism network marketing system planning, resulting in poor marketing.

\section{The Problem of Tourism Network Marketing in Dabie Mountain}

Through the investigation, we found that the following sections of the official tourism website of the following cities in Huanggang are uneven, and the website is better, such as Macheng, Hongan, Luotian County, the site planning is more mature, in the attractions, tourism products on the publicity more, But there is a lack of interaction in online transactions, consulting, and interaction with visitors. In the platform to show off, only such as Luotian, Ying Shan and other counties show the brand of Huanggang Dabie Mountain, the official tourism site lack of standardized construction, the lack of characteristics of the site, homogeneity, lack of site content. 
Through the survey found that Macheng, Hongan, Luotian, Ying Shan, Qichun and other official website are owned by the county official tourism bureau, by the corresponding travel network to provide relevant technical support, and Yingshan County and Xishui County network technology Support from the relevant network enterprises, the county has the local network of technical personnel is not sufficient. In the promotion of tourism products in the most attention is the interactive travel site and tourists, only Hongan, Xishui, Yingshan County set up online consultation and message section, but the browser found that most of the message content is outdated, obsolete and not timely Get a reply, the site technical maintenance staff did not timely maintenance of the site.

Huanggang Dabie Mountain tourist areas of the county have their own construction of the corresponding Dabie Mountain tourism website, but the county network platform is not strong linkage, many sites but information services are not in place.

First, Huanggang Dabie Mountain did not set up a dedicated official network platform, by clicking into the corresponding county and county tourism website, the Hobang Dabie Mountain regional tourism to do the overall publicity, the overall promotion, the overall marketing, there is no more comprehensive spindle platform, the integration of the following counties Of the tourist area network platform, the formation of the overall regional linkage purposes.

Second, Huanggang Dabie Mountain area cities and counties did not achieve the sharing of tourism network resources. For example, is to promote the natural scenery of Luotian and Yingshan County, are only in their respective network platform to promote their respective tourist attractions, not sharing tourism-related information resources, resulting in the loss of a large number of tourists. If the realization of tourism resources sharing is bound to produce linkage is in a certain range to retain more potential consumers.

Third, Huanggang Dabie Mountain area cities and counties did not do the tourist attractions network publicity coordination and cooperation. Huanggang Dabie Mountain tourist attractions, in particular, some tourist attractions seasonal strong, in order to highlight the characteristics of Huanggang Dabie Mountain tourist attractions, and better play the effectiveness of network marketing, the county and the scenic area did not form a tourist season network coordination and cooperation, spring Pay more attention to flowers, mountaineering and other activities, the main summer rafting and other activities. Such as the city of apricot apricot village scenic spot, the tourist season in the spring, and the British mountain Bi Shengda Grand Canyon area, the tourist season in the summer, so if the appropriate season in the main push the appropriate attractions, can get a good complement, but also Which will help better promote tourism products.

Visitors to visit the travel site is not just want to get travel product information, but also hope that the tourism site to organize supporting tourism activities, self-help tourists focus on access to their own information needed to obtain safe and smooth travel activities, so you need to travel advisory services Huanggang Dabie Mountain tourist area is not very perfect. Such as Hongan, Ying Shan, Xishui and other counties in the site platform to set up a tourism investment, will be able to make good use of network investment function. Another example is the Yingshan County official travel site in the existence of tourist routes recommended this plate, but only in the form of text and pictures show, and can not greatly arouse the interest of tourists, if the official website in the perfect booking, set hotel catering Function, I believe that tourist attractions can greatly reduce the cost of publicity, access to higher tourism revenue.

\section{Huanggang Dabie Mountain Tourism Network Marketing Recommendations}

The site is the facade of the tourist area, according to the characteristics of Huanggang Dabie Mountain tourist area planning network, lay the foundation for network marketing.

First, the website publicity effectively show Hokkaido Dabie Mountain counties and cities tourist attractions characteristics. As the Huanggang Dabie Mountain tourist area flagship red tourism, green eco-tourism and cultural landscape tourism, so the site design can make full use of red, green background color, highlighting the tourism characteristics. Such as Hong'an County should be the main publicity Tiantai Mountain Scenic Area and the revolutionary martyrs relics and other tourism 
features; Ma Chengxian propaganda turtle mountain and martyrs commemorative features; Yingshan County mainly promote folk culture and eco-tourism characteristics, the main push "Bi Sheng hometown, silk tea (Hot spring), famous (tea, silk, wild vegetables), celebrities (Bi Sheng) and other rich landscape of human resources.... Luotian main propaganda thin blade, heavenly village and other natural ecological scenic area, Qichun is the main push tourism leisure health tourism.

Second, improve the county and township tourist attractions site plate content settings. Huanggang Dabie Mountain tourist area of the county's travel site on the home page can be as simple as possible, less text, the plate to streamlining the practical, better travel site section of the main set of scenic spots, news center, travel guide (scenic traffic, scenic guide Scenic spots, tourist attractions, travel shopping), travel Raiders, pictures and video display, travel services and visitors to interact, contact scenic spots, and for the country's high visibility of the tourist attractions, travel sites can be added booking, booking, booking hotel And other functional plate function.

Third, improve the tourism website system function. Huanggang Dabie Mountain Tourism official website and the county and county tourist attractions website should improve the site system functions, such as the release of tourist information, scenic navigation demonstration, landscape pictures and video display, traffic information and weather inquiries, online travel $\mathrm{Q} \& \mathrm{~A}$, online survey Management, travel complaints feedback. According to the specific situation of the Dachan Mountain counties, if the tourist attractions are highly known and the tourists are strong, they can also add tickets, travel forums and other functions. In addition, the Huanggang Dabie Mountain area between the scenic site and the official website should be Huanggang City as the main axis, the joint Hongan, Macheng, Ying Shan, Luotian, Qichun County, and contact other tourism industry website publicity and promotion, the specific performance For the website designed in the links, can effectively strengthen the link between each other.

Fourth, with the official website of Huanggang City, Huanggang City, the official website to introduce the scenery of the county and the characteristics of the attractions. You can also link to the county and county cities to see the official website of the county, so as to get more detailed scenery and attractions of the introduction. This allows visitors to more clearly understand the understanding of the attractions of Huanggang County, and do not miss any one of the attractions.

First, the Huanggang Dabie Mountain tourist area below the county and scenic spots should pay attention to the use of tourism network marketing, not just to see it as a form, to the value of formal tourism network marketing.

Second, the Huanggang Dabie Mountain tourist area should focus on the establishment of the relevant tourism network marketing department, the introduction and training of the relevant tourism network marketing personnel. Huanggang City can join the following counties, to carry out tourism business staff of the network marketing and e-commerce professional and technical training, design special training courses, and invited at home and abroad, better development of domestic and foreign travel agencies, the Ministry of Industry and the National Network Information Technology Examination Management Center and other units Travel network and marketing experts.

Third, the counties and cities should also be combined with the actual situation of various tourist attractions to carry out tourism scenic network marketing site planning, network technical staff arrangements, so as to avoid blind, impulsive, disorderly to carry out tourism network marketing in order to more effectively save Cost, benefit.

Fourth, to strengthen the Huanggang Dabie Mountain area of the county tourism area network marketing coordination and cooperation is the common construction of Huanggang Dabie Mountain tourism website. The Dabie Mountain counties and cities of the tourism resources to be classified, with a large network platform scientific and reasonable to Huanggang Dabie Mountain rich tourism resources show in front of tourists.

Because the network has a good cross-time and space, so the Hokkaido Dabie Mountain area of tourism enterprises do not need to promote cross-regional business, do not just consider a certain source of the market, this feature can be a good savings in business costs

In the Huanggang Dabie Mountain on the basis of the official website, co-ordinate the counties 
and cities, tourist attractions tourist sites, and Huanggang Dabie Mountain scenic areas of the hotel, catering business cooperation, improve the site facilities, but also through the national travel agencies, Tourism information website to form a strategic alliance, to promote the promotion of tourist attractions brand. The site can also be established with the airlines, bus tickets, train tickets, ticket agent point of cooperation, improve the travel site traffic ticketing function, through cooperation with the bank to increase the network booking, ticketing function. So that visitors can visit the tourist site more convenient and quick access to travel facilities services.

First, the Huanggang Dabie Mountain tourism through the micro-blogging media platform, through the display of text, pictures, video information, the use of micro-blogging marketing, full display of tourist destination image, improve the tourist attractions brand awareness. Huanggang Dabie Mountain tourist area counties and cities can apply for official certification of micro-blogging, through the release of the Dabie Mountain tourist area of the relevant tourist information, so that more people understand the Dabie Mountain tourist area, but also on the Huanggang Dabie Mountain tourist attractions tourism resources, history and culture, Folk customs, personalized service and tourists with multi-level, multi-faceted, multi-angle communication, to stimulate consumer travel motivation, which is the core of micro-blogging marketing. For example, in 2010, Huanggang held in China Huanggang Dabie Mountain Tourism Festival, including the red (red memory), Luotian (Dabie charm), Ying Shan (tea house song), Qichun (medical St. legacy), Huang Mei (ancestral In the Huanggang Dabie Mountain micro-blogging can introduce the event, and upload the festival during the characteristics of photos, video features, so that Internet users to participate and discuss, to improve visibility.

Second, QQ, WeChat marketing is the era of network economy business model of innovation, is accompanied by the rapid development of Internet communications, a network marketing. As the QQ user base and information dissemination speed, a wide range, low cost, Huanggang Dabie Mountain tourist area and the county tourist attractions can apply for official QQ users, through the establishment of QQ group, to attract potential tourism consumer groups, but also through the QQ mailbox Mail marketing, in the QQ signature and personal description page can be added Huanggang Dabie Mountain Tourism official website URL link. Such as the Yingshan Grand Canyon and Macheng Tianjingshan Grand Canyon Scenic Area, can be set up on the QQ lofty lovers QQ group, because QQ popular in young people, so the establishment of QQ group must be able to achieve the effect of a call, drifting lovers through group discussion, And enterprises in the QQ group within the appropriate release of Yingshan and Macheng Grand Canyon drifting scenic spots, can be a good way to improve the Ying Shan, Macheng tourist attractions of the visibility. The same QQ and WeChat platform can also be used as a tourist business and tourist communication channels, so that compared to the official travel site to communicate and data collection can play a better effect. And the WeChat is mainly used for network push and communication services and other purposes, Huanggang Dabie Mountain tourist area can apply for certified users, by absorbing WeChat users and the appropriate release of tourism information and tourism activities of the push, which is now among the young people are extremely common. As the popularity of smart phones nowadays, Huanggang Dabie Mountain area through the smart phone terminal push Huanggang Dabie Mountain tourism information.

\section{Acknowledgements}

Huanggang Normal College 2016 annual high-level cultivation project, project number: 201619203;

Research on the Construction of Rural Tourism E - commerce Platform in Dabie Mountain in Hubei Province under the Background of "Internet +"

\section{References}

[1] Victor T.C. Middleton, Alan Fyall, Mike Morgan, AshokRanchhod: Marketing in travel and tourism [M]. London: A Butterworth-Heinemann, 2009: 126-131 
[2] Wang Guiying, Dong Chunxiao. China's tourism network marketing problems and countermeasures [J]. Commercial Modernization, 2006, (31) 